\title{
The Mandala of Managerial Joy ${ }^{1}$
}

\author{
Kazimierz Kuciński \\ Economic Geography Faculty, Collegium of Business Administration \\ SGH Warsaw School of Economics
}

\begin{abstract}
Management means combining the art of exercising it and the managerial science about it. It grows out from culture, it is one of its elements as well as a factor affecting it. It is like a mandala made from grains of managers' experience and knowledge, as well as the values they declare. The formation and creative destruction of such a mandala is something like poetry, because it needs some talent and imagination. When managing, one develops many virtual, and sometimes real different mandalas showing various aspects of management. The most important is the mandala of managerial joy. Experience of such joy depends on the way a manager perceives reality. It requires from the manager the following attributes: perspective, humility, humor, acceptance, forgiveness, gratefulness, compassion and generosity as well. This article explains the essence of the pillars of managerial joy and describes how to understand them.
\end{abstract}

Keywords: management, art, mandala, joy

\section{Introduction}

It happens that managers experience discouragement. Despite making all efforts and despite having all the required competences for what they do, they are sometimes dissatisfied with the effects of their actions and the actions themselves. This situation frustrates them. Realizing that, they ask themselves what their actions were short of that they cannot feel satisfaction from what they do and the way they do it. They wonder how and where this missing element can be found, if it has been lost or whether it has ever existed.

1 Considerations herein, regarding the issue of being a good boss were inspired by published in 2017 by Znak Publishing House, Wielka księga radości [The great book of happiness], a record of a discourse moderated by Douglas Abrams, which took place in April 2015 in Dharamsali between Tenzin Gjaco XIV Dalajlama and Desmond Tutu, talking about the joy and happiness in the world full of suffering and evil. Cf. A. Szostkiewicz (2017, pp. 18-20). 
This element is the joy originating from managing people, organizations or projects. If it does not accompany our directing management, when it is clear that there is no happiness among those who we manage or those who we work for, the growing frustration deteriorates the emotional condition of a manager more and more and their management. In order to get rid of the frustration, one can perceive his/her directing management as a mandala, and at the same time to look in the heritage of human thought and human experience for inspirations and recommendations on how to find the joy from one's efforts, the way they are made and what the joy should be based on as well as how to savour it.

There are many ways leading to this joy. One of them is presented in this essay. Its massage is based not on the management theory, but it verbalizes the long-term experience of the author and the afterthought on how he managed, what he managed and how he should have done it in order to feel the joy. Hence, it is a very subjective perception of the directing function of management. However, in my opinion it can be found to be a sort of recommendation for managers, in particular for those who no longer feel they really want to do their job and the incoming challenges seem to overcome them.

\section{Management as a mandala}

Paraphrasing two first lines of the song popular in the past, performed by Jerzy Stuhr, ${ }^{2}$ many people think that everyone can manage "sometimes in a better and sometimes in a worse way", since the final result is not the most important, and the further part of the song states: "I can handle it for sure". However, this is not right since management is not simple and consequences of it are far-reaching for all the members of this process including managers. Management is not easy and it requires considerable skills, predispositions and even more - talent. Not everyone has and can have the afore-mentioned skills and predispositions. Management is something what Anglo-Saxons call 'art', something within the definition of 'art' considered to be an antonym of what in the English language is called 'science'.

Nearly 200 years ago this issue was dealt with by Nassau William Senior who said that "...economics had been art first, then it became science". ${ }^{3}$ If management is considered to be a disciple of economics, which is a synonym of traditionally recognized economy, this also concerns management. Firstly, by the trial and error method there emerged the art of management and then, relatively much later,

\footnotetext{
2 "Everyone can sing, in a better or in a worse way, since the way is not the point."

3 N.W. Senior (1827, p. 28). Cf. M. Wojtysiak-Kotlarski (2011, p. 39).
} 
there was developed a scientific thought regarding this art looking for its universal regularity and making an attempt to identify the mechanism of management as well as conditions under which it functions.

Learning about these regularities and this mechanism and conditions of its desired way of operation enables us to establish recommendations on how to manage in order to make the action praxeologically effective and economically efficient and at the same time, socially and ecologically responsible and accordant with the principles of sustainable growth. The point is not to manage in a technocratic way because of pure economism, the point is to manage economic entities, organizations, processes, projects and, in particular, human teams and to do it in the way which Plato called a combination of the good and the beauty, not forgetting about the truth.

It seems to be unattainable since it requires constant and effective facing a sort of squaring the circle. It is an arduous pouring of a kind of managerial mandalas comprising many-coloured grains of managerial and human experience, scientifically developed recommendations concerning the management which is a 'god job' in the meaning of T. Kotarbiński, the specificity, utility and usefulness of particular actions as well as all the circumstances of it adjusted to the place and the time.

It is a stubborn way to combine the circle symbolizing great ideas and truths included in books, along with down-to-earth existential ordinariness of this world symbolized by the square. The success of this undertaking requires, most of all, realizing what is a centre point of such a managerial mandala, and what is around it; one needs to catch what is the beginning and, at the same time, the end of the developed figure.

Such mandalas are made in order to manage wisely what has been entrusted to us, in order to realize goals to be achieved or, just to re-think the whole thing again and do everything once again in a good and stunning way, in order to leave the circle of the darkness and the routine due to the control of one's own body and the mind, by meditation, wise books and advice from one's guru. It requires one to destruct the already made mandala and to make a new one, the same one but different.

Management is indeed just painstaking pouring and inspiring re-pouring, creation and destruction of such virtual and sometimes real mandalas extracting the harmony from the chaos. They make all what comes from it, which becomes an effective, efficient, productive, responsible and, above all, useful and intentional action. Pouring them and destroying them can be a metaphorical inspiration for such management and for scientific analysis of its essence and conditions; moreover, they should be looked for in an isomorphically considered art, in varied 
types and signs posing together what we call culture, part of which is management itself.

This inspiration is included in the mandala of love, peace, health, wealth, case, hope and many other ones related with varied management spheres and nuances, expressing them symbolically. All of them are important but the most important one is the mandala of joy originating from management, experienced by a manager, colloquially called the boss, especially that all depends on him/her in the end.

\section{The mandala of managerial joy}

To be the boss means to assure daily an economically efficient, praxeologically justified and safe economic performance and development of the subordinate organization (entity) by being its acquiescent leader (manager), and above all, the leader who is enthusiastic and can promote his/her enthusiasm among those who he/she works with. To be the boss means to do the good job which, like any other, should give joy and give happiness to all who are involved in the process including the boss himself/herself.

In fact, being the boss should be a source of joy for the one who is the boss and for those who are subordinated to him/her as well as for the managed entity. This joy and the resulting sense of happiness cannot be just a side effect of a hunt for other goals of a particular organization and for the personal successes of its boss. This joy must be hunted consciously, one needs to remember that sources of joy are in our minds and emotions.

There are located pillars of happiness because of the job which is carried out. Thanks to them our actions are satisfying for those who we take them with and bring the joy for those who we take the actions for. These pillars are a way the reality image is perceived rooted in the mind sphere, supported by humility and the sense of humor as well as the accompanying acceptance, and in the sphere of emotions, readiness to forgive, to feel and to show gratitude, compassion and generosity.

A good boss cannot look at what he/she manages and those who he/she manages as well as the conditions in which he/she operates from one perspective only. He needs different angles of view since reality is much more complicated than we think. And we ourselves are more complicated than we think.

In order to do the things we do in a correct way and to see the complexity of the conditions affecting our actions, we need to learn about ourselves and understand ourselves, in order not to be a problem for ourselves. It is an issue of identification 
and verbalization of my own identity in order to determine who I am, what my strengths and weaknesses and goals are, and whether or not I can control my emotions - the positive and, even more, the negative ones.

Learning about oneself (gnothi seauton) is the primary task in our modern civilization. It requires actions, since the actions, related behaviours and thoughts enable one to understand himself/herself and to find out who he/she is, what kind of a human he/she is and what is his/her social role. However, one cannot learn about oneself just by meditation and contemplation of himself/herself. Knowing oneself requires work on oneself in order to become the desired one and a one who fulfills the assigned social role. This work on oneself is necessary but moderation is required. Our nature must be enriched and enhanced, and the most valuable things must originate from it for the need of the played social role; nevertheless, this nature must not be oppressed. ${ }^{4}$

It is not simple since we have great problems when it comes to the determination of our identity. Appearances are misleading and we do not know who we are, where and why we are going. Usually, we want to be someone else than we are and especially to be perceived as someone else. The problem is, however, we do not know exactly what we want and how we want to be perceived. What is more, we do not know why and what for we would like to have other identity than the one we have.

It is hard for us to be ourselves but even harder it is not to be ourselves and, if we are bosses the difficulty in question is particularly overwhelming and it hampers our correct thinking about our tasks and their implementation. It turns out that thinking in terms of 'I and mine' certainly does not promote being a good boss. It is neither good for us nor for those who we manage and the entity we are responsible for. A good boss always thinks 'we and ours'. When managing others, it is necessary to have a great ego, nevertheless, a too extended ego is hazardous for managerial roles and sometimes it damages their efficiency and productivity. A good boss knows, too, that freedom is indeed useful and given to him/her but he/she is also aware of the fact that it is useful and given to his/her subordinates, as well as to all external co-partners, competitors and customers.

The way of looking at the reality where we operate is our last and inalienable freedom and its boundary is the freedom of those who we work with and those who we work for. Being free and taking benefits from the freedom, the boss must respect this freedom, insure it and secure it.

4 Cf. interview of Agnieszka Jucewicz with Bartłomiej Dobroczyński, published in a supplement to the Gazeta Wyborcza of 27 January 2018 - Wysokie obcasy, 3(966), under the title "Kop", 27 January 2018, pp. 20-25. 
Selfishness is indeed given to us like freedom but it should be a wise selfishness forcing us to think of others without neglecting their needs, according to the principle 'leben und leben lassen' (live and let live). In fact, some altruism is necessary to become successful in the area of people management. It is the 'philosopher's stone' of the search for joy and happiness arising from obsequious people management and from being a leader for them.

In this activity one needs to see the relationship between us and our actions and what makes the basis for them, as well as what their results are. The point is that these activities must be placed and seen in a wider context and one needs to realize that we are just an element of a certain structure having the system nature. Nature is what defines our destiny, and what we have is just an ability to adapt creatively to these structural conditions, formal and informal ones.

Because of the fact that nothing is forever, also these conditions are variable over time and we change ourselves. Consequently, we start seeing in a different way and we must perceive things in a new way in order to notice many features we have not seen previously. Due to the changed optics, hazards and barriers frequently become new chances and opportunities.

Reality changes, but also our perception can evolve. And if we want to be good bosses, our perception must necessarily change, in such a way that the perception of the environment where we operate, the people we mange and the entity we manage becomes more and more extensive, diversified and multidimensional.

Good knowledge of the subject and conditions of our actions is only holistic and updated one. We should acquire it in order to say, every morning, about our own organization and its people: "The change took place here when it comes to my point of view" (Mickiewicz, 1971, p. 109).

That awareness of variability should be a source of a good boss's humility. It is an extremely important aspect of being a boss, especially a good one. Being a good boss requires optimizing the necessary self-confidence with essential humility with respect to what one does and with whom. While making such optimization one should strive for humility to arm proud bosses and for humble bosses to acquire angry pride (Tuwim, 2014).

For one should always remember that none of us is perfect. Though we make effort to improve ourselves, absolute perfection is out of our reach. We may and we should aim at it without forgetting that one may be the boss at times, not all the time. The belief that he/she is irreplaceable and better than any one of his/her subordinates is the beginning of every boss's end.

It is worthwhile, therefore, while being the boss, to think how I would feel in my subordinate's shoes and how I will feel becoming one of them, having ceased being their superior. Being the boss, we must not forget, not even for a while, that social roles we perform are highly volatile. 
Besides, being the boss, we must not forget about having our own boss, and even if there is no such a boss, there is someone who is above us - the boss of the bosses, the boss of all the bosses and their superiors, who being the boss seems to act as if he/she was not the boss whatsoever.

The measure of the boss's greatness is the ability to remain humble. Thus, a good boss should repeat a Buddhist mantra several times a day, saying to himself/ herself: "Whenever I meet another man, I hope I will not feel better than them".

A wise boss does not dazzle with wisdom, even if he/she is aware of being wise. $\mathrm{He} /$ she does not do it especially when dealing with individuals whose IQ is slightly lower. He/she knows his/her wisdom is supposed to serve a purpose. It is good he/ she is wise but this is not a reason for boasting about it and feasting one's mind about it, and in particular for giving oneself airs, simultaneously giving vent to one's primitive vanity.

Being the boss, in the long run in particular, gives rise to an inclination to vanity and putting on airs, which is deadly for good performance of the function. It is particularly dangerous in Polish social, historical and cultural conditions. Unfortunately, there is an unrestrained need for domination in us, Poles. ${ }^{5}$ By all means we want to be above someone, to exercise power but not in order to do something good but, above all, to bask in the power and to take revenge for many centuries of humiliation of a manor fornal, a serfdom peasant or a downgraded nobleman.

We want once more, usually in a subconscious way, at least for a moment to be the lord in a manor house, and even better in a magnate palace, and since there is an opportunity to do so, even if only seemingly, why not use it. We seem to forget that "a flunkey will always remain a flunkey" (Witkiewicz, 2017), and a "peasant lord' ${ }^{6}$ is just grotesque, if not pathetic.

In order to protect oneself from this ridicule and pride, which impairs good performance of the function of the boss, one has to be humble. A sense of humor helps to be humble, especially as Jacques Lassalle used to say: "what's the funniest, it's the deepest", whereas according to Oscar Wilde: "seriousness is the only escape for shallow minds".

A sense of humor proves spiritual development and intellectual maturity of those who demonstrate it. For laughter and jokes are better than excessive seriousness and, in particular, groundless swank. They help establish social

5 If we become aware of its appearance, it is worth thinking critically about it, bearing in mind the concept of personal and social power as defined by D. C. Clelland.

6 Cf. $€$. Tarnowsky, Z chłopa pan, and Adamus, There's no worse a devil than making a lord out of a peasant. Polski Portal Literacki. Retrieved from: https://poezja.org/dzial/4-wiersze 
relations, break social barriers, build social capital, so important for correct functioning and development of every organization.

An ability to awaken joyfulness opens human hearts, especially if we can laugh at ourselves, because it shows that we are not conceited.

Humor and a bit of distance to ourselves and what is happening around us are particularly important in crisis situations. They allow us to relieve tension, inhibit aggression, they become catalysts of positive energy, even in the saddest circumstances, especially because, as Charlie Chaplin said, "at the bottom line everything is a gag".

A smile can do much more than screaming and having a grave face. While performing managerial functions with a cordial smile on one's lips, it is done with charm, gaining a sophisticated lightness of management, which makes it not only effective, but also pleasant, both for the managers and the managed.

A sense of humor also facilitates the constructive acceptance of the conditions in which the boss comes to act, especially those hindering the achievement of the goals set or imposed. Managing and performing managerial functions is easier when we come to terms with the autonomy of reality, which is as it is and not necessarily as we would expect it to be.

However, accepting this fact does not mean a fatalistic endurance of all oppression. Accepting the conditions of our activity, its object and entities participating in it, we must not remain passive towards what hinders the achievement of our goals and what is clear evil.

Constructive acceptance means, therefore, that there is no point in worrying about what cannot be changed, especially what can be changed and what needs to be changed for it to be adapted to our needs and expectations. Such constructive acceptance of the activity conditions is the first step towards the change that is necessary, especially if it is really good, serves the good and leads to the good.

By accepting constructively the subject of management and the people managed as well as the environment in which the management takes place, a good boss may find joy in what he/she does, especially that in the end it turns out that everything is actually going for the good, or at least it should, as long as we slightly improve the conditions of our activity.

In order for this to be possible, a good boss must look at what he/she is doing prospectively, freeing himself/herself from the past, taking from it only what is necessary to maintain continuity, experience and heritage, and especially good practices developed over the years. The past must be valued and skillfully used, but one must not get stubbornly stuck in it, especially if the past was clearly bad.

One must not fuel trauma, seek the harm suffered, be guided by a desire to retaliate, be vindictive and unforgiving. Being guided by 'an eye for an eye, a tooth 
for a tooth' principle in management makes the boss blind and weak, and thus ineffective. A good boss must be able to forgive, because forgiveness is the proof of his/her strength. It does not mean at all the acceptance of what was wrong in the functioning of the managed organization, in the work of the predecessors, in the behaviour of subordinate employees, in the conduct of co-workers, cooperators, competitors and customers, and public authorities. For forgiveness is not tantamount to oblivion. However, it is about treating what we forgive as a kind of experience, as an element of knowledge about those with whom we work and for whom we make the effort.

Thanks to this knowledge we know what may possibly happen to us and we can look for ways to counteract the reactivation of what is unacceptable, because evil cannot be accepted, even a small one, seemingly unimportant. Not named and not condemned, it grows and becomes a source of destruction of us, our team and the entity we manage.

A good boss must be able to forgive evil constructively, but he/she must also be able to show gratitude to those from whom he/she receives good. First of all, one should give thanks every day for being who one is, being where one is and being with those with whom one is. And while thanking for all that, he/she should try to do his/her utmost not to waste it, but to multiply it. Thanksgiving for what one has, for what one has received from fate and people, helps enjoying all that.

However, the point is not to do it in secret, but to show it, especially to our co-workers, cooperators, competitors, especially customers, so that they know how much we value what they have done for us, what they have given us, or what they have prevented us from doing. Their good work and cooperation is a gift for us, because it makes our work easier and sometimes even it makes it possible. We should be grateful to them for their deeds, showing gratitude and emphasizing that we treat what they do as something done for us personally.

Such gratitude boosts our spirits, but also gives joy to those whom we show it to, and also creates many new opportunities. Gratitude increases, and often gives rise to a sense of happiness, and what is not without significance, eliminates the stress caused by the inevitable negative emotions that accompany the boss's work.

Being able to see what has been given to us, being able to be grateful for what we get every day, we are ready to feel compassion and generosity, without which it is impossible to be a good boss, and especially to derive joy from being the boss or, as we said earlier, being the boss at times.

A good boss should like those he/she manages, directs and leads, showing compassion. He/she may have a lot of things on his/her head, but he/she must not forget that his/her subordinates are people with their own weaknesses and troubles. Therefore, they require care, empathy, interest in their personal matters. 
They know that they are only part of a big and sometimes even huge team, but they want to be treated individually.

They want the boss to see not only their skills and professional competences, but also their unique personality and the fact that they not only work, but also that they live and devote a large part of their lives to professional work.

That requires a good boss not only to focus on the organization he/she manages, but also on people owing to whom it is what it is. Emphatically focusing on his/her team, a good boss must not forget about himself/herself. A good boss should take care of each of his/her subordinates, but he/she is also obliged to take care of himself/herself, both for selfish and altruistic reasons. And if he/she cares for himself/herself as much as he/she cares for his/her subordinates and sympathizes with them, there is no reason for him/her to be ashamed of it.

Compassion and the accompanying empathy are needed on a daily basis, but they become particularly important in need which is a time of trial for our subordinates and for ourselves. It is a challenge that needs to be met with the awareness that by giving we get. For compassion must be accompanied by generosity inextricably linked with it.

Magnanimity and munificence, however not only material but spiritual, are the symptoms of generosity. It exemplifies that in order to satisfy our needs and desires, we need each other.

A good boss knows that and expresses it, devoting himself/herself to his/her company and his/her staff. He/she does it as he/she knows that "real happiness comes from joy from a well fulfilled obligation, from the delight about creating something new" (Antoine de Saint Exupery, 2017). To feel this joy is not just a personal matter for the organization's manager. This joy should translate into the economically safe performance and development of the organization in the specific conditions resulting from its specific nature and the characteristics of its location, as well as its operating space.

The point is, therefore, firstly, to experience such joy selfishly and, at the same time, to be able to transform it into an altruistic benefit. For the former to be possible, one simply has to act by doing what one does not because one has to do, but because one wants and likes to do it, one strives for it. The implementation of the latter requires social acceptance of the action by the beneficiaries of its results. For the joy of management to be satisfactory for the manager, the managed and the external partners, the boss's actions must be fully accepted by them, so that one knows that what one does, who one is, what is important to them is appreciated, and one's substantive and managerial competences are widely recognized.

However, this joy is of no use and ceases to be joy when the person who feels it begins to value his/her emotional state retrospectively and prospectively, 
believing that the joy he/she feels is not as it used to be and as it could be, and especially fears that he/she will not experience it again in the future. Avoiding such a situation requires full concentration on what one is doing and feeling, and in fact contemplation of the resulting joy, as if one was not aware of its existence. The joy felt in such a way, coming from action leads to continuation and intensification of the action, especially when it is well-deserved and results from own efforts of the doer who does what he/she does without asking himself/herself or those for whom he/she does it the question 'why' he/she does so.

\section{A bit of poetry}

Therefore, if management is to be a praxeologically efficient activity, practically useful, economically effective, socially and ecologically responsible, and at the same time emotionally satisfying the one who manages, those whom he/she manages and for whom he/she manages them, then it must have something of the metaphysical, as though religious ecstasy experienced during mandala pouring and its conscious destruction. It must be immersed in culture, grow out of it and create it being treated in itself as a specific kind of art and a component of that culture. It must be similar to the creation of poetry (Kuciński, 2010), rooted in what has already been written about the beauty of the earth and the sky and about human feelings and deeds, and at the same time experiencing, interpreting and showing it all in a completely different way, because of perceiving what others looked at, but did not see and finding a new form of expressing it. As management has not only something of a mandala in itself, but also of poetry understood that way, because creating and destroying a mandala is poetry in itself, just as it is a kind of pouring and scattering a mandala arising from feelings and words. Management, like poetry and poetry, like management, require fantasy, lightness, abstract thinking, simultaneous analysis and synthesis, unexpected associations, searching for non-obvious and unknown paths, and above all, an unconventional form. It requires asking difficult, atypical and sometimes very uncomfortable, at times seemingly stupid and even meaningless questions, and above all, getting rid of the fear of asking them and giving answers to them. It requires concern for what is managed and those who are managed. It has to be something extremely important for the manager, something that absorbs and develops him/her, gives satisfaction and joy from a well-done job.

To make it possible, it is not enough to pour a mandala of joy, cherishing its beauty and poetry, and enjoying the good that it brings. Wishing for the joy whose secret is contained in this mandala to last, it must unfortunately be destroyed 
and poured again, as if it were the same, but different, so that what should last lasts, and especially what must be created in the world changing with us is born and revived.

\section{Conclusion}

If you are a manager of an organization, a project or a human team, having read these words, having considered the sentences and thoughts they contain, it is worthwhile referring to your emotional states and the dilemmas of a team leader. Having done this vivisection, it is worth trying to answer a rhetorical question asked between the lines of this essay, namely: Do I bring joy to others and myself while managing people, organization, projects, and does the fact that I do, makes me joyful? Regardless of whether the answer to this question is positive or negative, having assigned sand of appropriate hue to each sphere of an implemented management process, it is good to start pouring mandalas which symbolize this management, thinking critically and constructively about it and each of its elements at the same time. They must be poured until it becomes clear where, in the specific case, the multi-faceted viewing of the object of management, its conditions and implications are or should be displaced, and they are humility, humor, acceptance, forgiveness, gratitude, compassion and generosity without which management cannot be joyful and without which it is incapable of bringing joy. And since it is a dynamic process, one has to pour new mandalas depicting it, finding joy in pouring them, because it is not only about deriving joy from management, but also about rejoicing the search for joy that should be provided thereby, and especially finding the essence of its pillars in the changing world.

\section{References}

Dalajlama (Tenzin Gjaco XIV Dalajlama), Tutu D. (2017). Wielka księga radości. Kraków: Znak.

Jucewicz, A. (2018). Kop. An interview with Bartłomiej Dobroczyński, Wysokie obcasy, No. 3(966), a suplement to Gazeta Wyborcza, 27.1.2018.

Kuciński, K. (Ed.) (2010). Metodologia nauk ekonomicznych - dylematy i wyzwania. Warszawa: Difin.

Mickiewicz, A. (1971). Sen z Lorda Byrona. In: A. Mickiewicz, Dzieła wszystkie. Vol. 1, Wrocław - Warszawa - Kraków - Gdańsk: Zakład Narodowy im. Ossolińskich. Saint Exupery de A. (2017). Mały książę. Toruń: Algo. 
Szostkiewicz, A. (2017). Osiem filarów radości. Polityka, No. 51/52(3141), 18.12-26.12.2017.

Tarnowsky, Ł., Z chłopa pan. Polski Portal Literacki. Retrieved from: https://poezja.org/ dziela/4-wierszegotowe

Tuwim, J. (2014). Kwiaty polskie. Warszawa: Czytelnik.

Witkiewicz, St. (2017). Szewcy. Wrocław: Siedmioróg.

Wojtysiak-Kotlarski, M. (2011). O metodologii nauk ekonomicznych. Warszawa: Oficyna Wydawnicza SGH.

\section{Kazimierz Kuciński}

Full Professor at SGH Warsaw School of Economics; he graduated from the Faculty of Economics of SGH Warsaw School of Economics and he has been its academic \& didactic employee since 1972. He completed his $\mathrm{PhD}$ degree in 1976, became a habilitated doctor in 1989, and in 1998 he became a professor of economics. From 1994 to 2006 he was the head of the Institute for Functioning of the Domestic Economy at SGH Warsaw School of Economics, and since 2006 he has been the head of the Faculty of Economic Geography. He is interested in the theory of economic geography, regional growth, location of enterprises and their economic safety. In this context, he is especially interested in globalization processes and glocalization. Recently he has been focused on the methodology of economics and methodology of scientific research of economic phenomena and economic entities. 